IMAGEN EN LA PRÁCTICA CLÍNICA

\title{
Pericondritis auricular post-piercing producida por Pseudomona
}

\author{
Post-piercing auricular perichondritis produced by Pseudomona
}

Gustavo A. Lizardo Castro, ${ }^{1}$ Martha P. Zavala Sierra. ${ }^{2}$

1Pediatra, Sub-especialista en Dermatología Pediátrica, Departamento de Pediatría, Servicio de Dermatología, Hospital Escuela; Universidad Nacional Autónoma de Honduras (UNAH); ' ${ }^{2}$ édico Residente Tercer Año, Postgrado de Dermatología, Facultad de Ciencias Médicas UNAH; Tegucigalpa, Honduras.
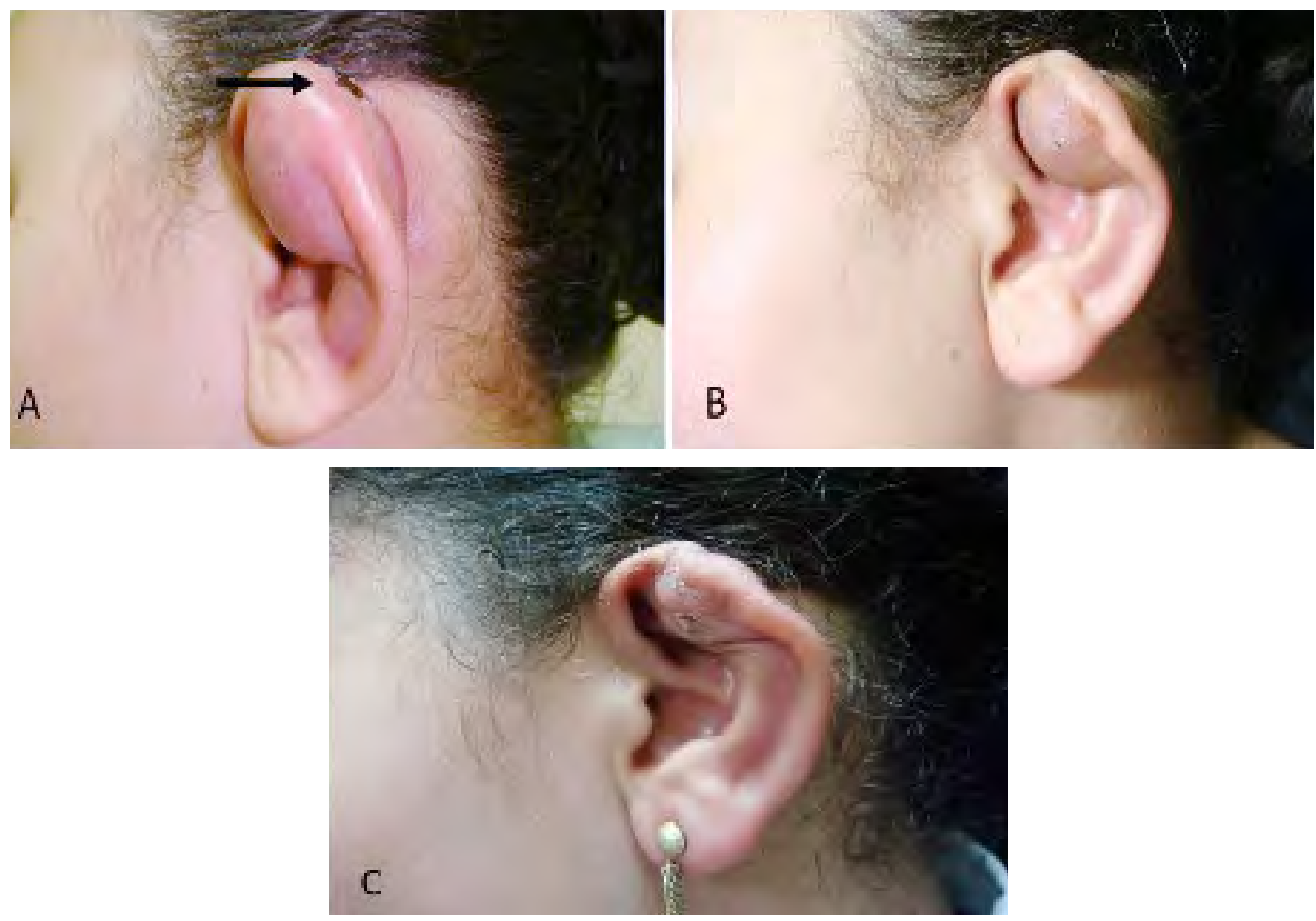

Femenina, 12 años, con antecedente de perforación o piercing en oreja izquierda, un mes antes. Una semana después presenta signos inflamatorios con formación de absceso en hélix y antihélix, drenaje espontáneo de pus y costra hemática (Figura A) en sitio de piercing (flecha), habiendo recibido tratamiento con amoxicilina sin mejoría. Se realizó drenaje y cultivo, se indicó oxacilina/amikacina parenteral, obteniendo mejoría (Figura B); al aislarse Pseudomona aeruginosa se cambió a ciprofloxacina oral, $500 \mathrm{mg}$ cada 12 horas por 14 días, resolviéndose proceso infeccioso, con deformidad residual del pabellón auricular (Figura C). Los piercings, en la actualidad son de popularidad creciente en adolescentes femeninas, efectuados en el tercio superior del pabellón auricular, donde dada la naturaleza avascular del cartílago se complican una tercera parte de los casos, siendo la pericondritis la complicación más frecuente. Suele manifestarse en el curso de cuatro semanas, presentando dolor, eritema, edema y absceso, que debe ser drenado. El diagnóstico es clínico, confirmado por el cultivo. El tratamiento de elección en adolescentes y adultos es una fluoroquinolona, ceftazidime 0 vancomicina, según patógeno y sensibilidad antibiótica. Aún con manejo oportuno y apropiado, puede ocurrir necrosis del cartílago y deformidad permanente, como ocurrió con el caso clínico descrito.

Recibido: 05-07-2020 Aceptado para publicación 28-01-2021

Dirección para correspondencia: Dr. Gustavo Lizardo

Correo electrónico: glizardoc@yahoo.com

Declaración de relaciones y actividades financieras y no financieras y conflictos de interés: ninguno. 